\title{
The effect of mannitol on oxygenation and creatine kinase MB release in patients undergoing multivessel off-pump coronary artery bypass surgery
}

\author{
Jae Kwang Shim, MD, ${ }^{a}$ Seung Ho Choi, MD, a,b Young Jun Oh, MD, a,b Chang Seok Kim, MD,
} Kyung Jong Yoo, MD, PhD, ${ }^{c, d}$ and Young Lan Kwak, MD, PhD ${ }^{a, b, d}$

Objectives: Despite avoiding cardiopulmonary bypass, off-pump coronary artery bypass surgery is associated with reduction in $\mathrm{PaO}_{2}$ and postoperative respiratory compliance. Also, transient interruption of coronary flow is necessary during distal anastomoses and may impose ischemia-reperfusion myocardial injury. Mannitol is an osmotic diuretic with free radical scavenging properties, and we have evaluated the effects of mannitol on oxygenation and cardiac enzyme release in patients undergoing multivessel off-pump bypass surgery in a prospective, randomized, controlled, double-blind trial.

Methods: Fifty patients were randomly allocated to receive either $20 \%$ mannitol 0.5 $\mathrm{g} / \mathrm{kg}(\mathrm{n}=25)$ or normal saline $2.5 \mathrm{~mL} / \mathrm{kg}(\mathrm{n}=25)$ during Y-graft construction. Pulmonary variables and serum sodium concentrations were measured 15 minutes after induction of anesthesia and sternum closure. Creatine kinase MB was measured before and after the operation. Intraoperative and postoperative fluid input and output, time to extubation, and intraoperative hemodynamic variables were also recorded.

Results: $\mathrm{PaO}_{2}$ after sternum closure was significantly higher in the mannitol group, with faster time to extubation and shorter length of stay in the intensive care unit. Intraoperative urine output was significantly greater in the mannitol group, without significant differences in fluid input, serum sodium concentration, and hemodynamic variables. Number of patients with a creatine kinase MB level more than 3 times the upper limit of normal was significantly higher in the control group.

From the Department of Anesthesiology and Pain Medicine, ${ }^{\mathrm{a}}$ Anesthesia and Pain Research Institute, ${ }^{\mathrm{b}}$ Department of Thoracic and Cardiovascular Surgery, ${ }^{\mathrm{c}}$ and Yonsei Cardiovascular Research Institute, ${ }^{\mathrm{d}}$ Yonsei University College of Medicine, Seoul, South Korea.

Received for publication July 21, 2006; revisions received Oct 9, 2006; accepted for publication Oct 18, 2006

Address for reprints: Young Lan Kwak, $\mathrm{MD}, \mathrm{PhD}$, Department of Anesthesiology and Pain Medicine and Anesthesia and Pain Research Institute, Yonsei University College of Medicine, 134 Shinchon-Dong, Seodaemun-Ku, Seoul, South Korea, 120725 (E-mail: ylkwak@yumc.yonsei.ac.kr).

J Thorac Cardiovasc Surg 2007;133:704-9

$0022-5223 / \$ 32.00$

Copyright () 2007 by The American Association for Thoracic Surgery

doi:10.1016/j.jtcvs.2006.10.017
Conclusion: Mannitol could be safely used without adverse side effects in patients undergoing multivessel off-pump bypass surgery with beneficial effects in terms of preserving oxygenation, earlier extubation, and fewer patients with significant creatine kinase MB elevation.

$\mathrm{O}$ wing to advances in stabilization devices, surgical technique, and anesthetic management strategies, multivessel off-pump coronary artery bypass surgery (OPCAB) has gained increased popularity, with safety and early graft patency comparable with those of conventional on-pump coronary artery bypass grafting $(\mathrm{CABG}){ }^{1,2}$ Also, increasing numbers of studies have validated advantages of OPCAB over on-pump CABG with regard to shorter postoperative stay in the intensive care unit (ICU), less transfusion requirement, and lower cardiac enzyme release. ${ }^{2-4}$ Cardiopulmonary bypass (CPB) has been shown to induce systemic inflammatory response, producing increased pulmonary endothelial permeability and parenchymal damage. ${ }^{5,6}$ Despite avoiding $\mathrm{CPB}$, OPCAB is associated with decreases in $\mathrm{PaO}_{2}$, pulmonary compliances, and pulmonary function similar to on-pump CABG, which may lead to delayed extubation necessitating strategies for minimizing postoperative pulmonary impairment. ${ }^{7,8}$ In addition, temporary inter- 


$$
\begin{aligned}
& \text { Abbreviations and Acronyms } \\
& \begin{aligned}
\mathrm{CABG} & =\text { coronary artery bypass grafting } \\
\mathrm{CK} & =\text { creatine kinase } \\
\mathrm{CPB} & =\text { cardiopulmonary bypass } \\
\mathrm{ICU} & =\text { intensive care unit } \\
\mathrm{Na}^{+} & =\text {sodium } \\
\mathrm{OPCAB} & =\text { off-pump coronary artery bypass surgery } \\
\mathrm{PCWP} & =\text { pulmonary capillary wedge pressure }
\end{aligned}
\end{aligned}
$$

ruption of the coronary blood flow for bloodless anastomotic conditions may cause various degrees of myocardial damage. Although the period of target vessel occlusion is usually confined to approximately 15 minutes, multiple grafts may impose cumulative ischemia-reperfusion myocardial injury..$^{9,10}$

Mannitol is an osmotic diuretic with free radical scavenging properties used in many fields of medicine. ${ }^{11-13}$ During cardiac surgery, it can be administered in the pump prime and cardioplegic solution and has been shown to significantly decrease the wet weight of the lung after CPB and to reduce the extent of myocardial damage. ${ }^{14-18}$ However, there have been no studies validating the safety and effects of mannitol in patients undergoing OPCAB. Therefore, we have evaluated the cardiopulmonary effects of mannitol in patients undergoing multivessel OPCAB with regard to pulmonary compliances, $\mathrm{PaO}_{2}$, time to extubation, and creatine kinase $\mathrm{MB}(\mathrm{CK}-\mathrm{MB})$ level in a prospective, randomized, controlled, double-blind trial.

\section{Patients and Methods}

After approval of the institutional review board and patients' consent, 50 patients scheduled for elective multivessel OPCAB between January and June of 2006 were studied. Patients with pre-existing pulmonary and/or renal disease, serum creatinine level greater than $1.3 \mathrm{mg} / \mathrm{dL}$, left ventricular ejection fraction less than $40 \%$, unstable angina, and recent myocardial infarction within 1 month were excluded.

All patients received 0.05 to $0.1 \mathrm{mg} / \mathrm{kg}$ of morphine intramuscularly as premedication 1 hour before the operation. On arrival in the operating room, standard monitoring devices were applied, including a pulmonary artery catheter (Swan-Ganz CCOmbo $\mathrm{CCO} / \mathrm{SvO}_{2}$; Edwards LifeSciences, Irvine, Calif), which was inserted via the right internal jugular vein before induction of anesthesia. Anesthesia was induced with intravenous midazolam (2.0$3.0 \mathrm{mg})$ and sufentanil $(1.5-3.0 \mu \mathrm{g} / \mathrm{kg})$ and maintained with isoflurane $(0.6 \%-1 \%)$ and continuous infusion of sufentanil $(0.5-$ $\left.1.5 \mu \mathrm{g} \cdot \mathrm{kg}^{-1} \cdot \min ^{-1}\right)$. Neuromuscular blockade was achieved by administering rocuronium $(0.9 \mathrm{mg} / \mathrm{kg})$ and maintained with continuous infusion of vecuronium $\left(1-2 \mu \mathrm{g} \cdot \mathrm{kg}^{-1} \cdot \mathrm{min}^{-1}\right)$. Isosorbide dinitrate $0.5 \mu \mathrm{g} \cdot \mathrm{kg}^{-1} \cdot \min ^{-1}$ was infused in all patients throughout the study period. The patients' lungs were ventilated with a tidal volume of $10 \mathrm{~mL} / \mathrm{kg}$, an inspiratory/expiratory ratio of 1.9 , and an inspiratory pause $10 \%$ of total inspiration time at a rate of 8 to 12 breaths/min in $60 \%$ oxygen with air and no positive end-expiratory pressure during the operation. After induction of anesthesia, a transesophageal echocardiography probe was inserted to detect newly developing segmental wall motion abnormalities. Intravascular volume replacement was managed with crystalloid and colloid solutions to maintain the pulmonary capillary wedge pressure (PCWP) between 8 and $14 \mathrm{~mm} \mathrm{Hg}$ according to the baseline values before enucleation of the heart. Central temperature measured by a pulmonary artery catheter was maintained above $36^{\circ} \mathrm{C}$ with a warm mattress, forced warm air blanket, and fluid warmer as necessary.

After the arterial grafts were harvested, the patients were randomly allocated to receive either $0.5 \mathrm{~g} / \mathrm{kg}$ of $20 \%$ mannitol (mannitol group, $\mathrm{n}=25$ ) or $2.5 \mathrm{~mL} / \mathrm{kg}$ of normal saline (control group, $\mathrm{n}=25$ ) using a computer-generated randomization table. Infusion was done over 10 minutes during the period of composite Y-graft construction, and all medical personnel involved in this study were blinded to the content of the infusate bottle.

All surgical procedures were performed by one surgeon through a median sternotomy, and the heart was displaced with a posterior pericardial stitch, large $(12 \times 70 \mathrm{~cm})$ gauze swabs, and a tissue stabilizer (Octopus Tissue Stabilization System; Medtronic, Inc, Minneapolis, Minn). The sequence of grafting was always the left anterior descending coronary artery first, followed by the left circumflex coronary artery and the right coronary artery. During the period of heart displacement, mean systemic arterial pressure was maintained above 60 to $70 \mathrm{~mm} \mathrm{Hg}$ either with a $10^{\circ}$ to $20^{\circ}$ Trendelenburg position and/or norepinephrine infusion. Cell salvage was used during the operation in all cases, and salvaged blood was reinfused to the patient before the end of the operation. Allogenic packed red blood cells were transfused when the hemoglobin level was less than $8 \mathrm{mg} / \mathrm{dL}$ throughout the study period. All patients were transferred to the ICU after the operation.

Dynamic and static pulmonary compliances (S/5 Anesthesia Monitor; Datex-Ohmeda Inc, Helsinki, Finland) and $\mathrm{PaO}_{2}$ and serum sodium $\left(\mathrm{Na}^{+}\right)$level were recorded 15 minutes after induction of anesthesia (baseline) and sternum closure. CK-MB levels were measured 24 hours before surgery and 12 and 24 hours after surgery. Among the 2 postoperative values, the highest value was recorded and also the number of patients with CK-MB elevations greater than 3 times the upper limit of normal $(>15 \mathrm{ng} / \mathrm{mL})$ was recorded. Clinical diagnostic criteria for perioperative myocardial infarction were new $\mathrm{Q}$ waves of greater than $0.04 \mathrm{~mm}$ or a reduction in $\mathrm{R}$ waves greater than $25 \%$ in at least 2 leads, or both, new ST elevation in at least 2 contiguous leads measuring more than $0.2 \mathrm{mV}$ in leads $\mathrm{V}_{1}$ to $\mathrm{V}_{3}$ or more than $0.1 \mathrm{mV}$ in all other leads, or new left bundle branch block. ${ }^{19}$ Hemodynamic variables including heart rate, mean arterial pressure, central venous pressure, mean pulmonary arterial pressure, PCWP, cardiac index, and mixed venous oxygen saturation were recorded 15 minutes after the induction of anesthesia (baseline), 10 minutes after infusion of either mannitol or normal saline before enucleation of the heart, 10 minutes after stabilizer application for left circumflex coronary artery grafting, and 15 minutes after sternum closure. Amount of infused fluids and urine output during the operation and 12 hours in the ICU postoperatively were recorded. The amount of infused norepinephrine during the operation was also recorded. Extubation was managed according to the standard ICU protocols by the ICU 
TABLE 1. Patient characteristics

\begin{tabular}{lcc}
\hline & $\begin{array}{c}\text { Control group } \\
(\mathbf{n}=\mathbf{2 5})\end{array}$ & $\begin{array}{c}\text { Mannitol group } \\
(\mathbf{n}=\mathbf{2 5})\end{array}$ \\
\hline Age (y) & $63 \pm 8$ & $63 \pm 8$ \\
Gender (M/F) & $9 / 16$ & $9 / 16$ \\
Body surface area $\left(\mathrm{m}^{2}\right)$ & $1.7 \pm 0.1$ & $1.7 \pm 0.2$ \\
Diabetes (n) & 10 & 10 \\
Hypertension (n) & 13 & 11 \\
Preoperative medication (n) & & \\
$\quad \beta$-Blockers & 19 & 18 \\
$\quad$ Calcium channel blockers & 12 & 12 \\
$\quad$ ACEls & 14 & $62 \pm 11$ \\
LVEF (\%) & $63 \pm 11$ &
\end{tabular}

Data are expressed as mean \pm SD or number of patients, and all $P$ values were not significant. ACEls, Angiotensin-converting enzyme inhibitors; $L V E F$, left ventricular ejection fraction.

staff, consisting of cardiothoracic surgeons and anesthesiologists not aware of this study, and time to extubation was recorded. The criteria for tracheal extubation included an appropriate sensorium, hemodynamic stability with no significant chest tube bleeding, $\mathrm{PaO}_{2}$ greater than $80 \mathrm{~mm} \mathrm{Hg}$ with an inspired oxygen fraction of $0.4, \mathrm{PaCO}_{2}$ less than $45 \mathrm{~mm} \mathrm{Hg}$, and reversal of neuromuscular blockade. The length of stay in the ICU was also recorded.

Statistical analyses were performed with SPSS 12.0 software (SPSS, Inc, Chicago, Ill). All data are expressed as number of patients or mean $\pm \mathrm{SD}$. We determined that 24 patients would be required in each group with $90 \%$ power to detect a $50 \mathrm{~mm} \mathrm{Hg}$ difference in $\mathrm{PaO}_{2}$ between the groups with an $\mathrm{SD}$ of $50 \mathrm{~mm} \mathrm{Hg}$ and an alpha level of .05 using an independent $t$ test. Data between the groups were compared with the $\chi^{2}$ test, Fisher exact test, or independent $t$ test as appropriate. Changes between time points within the groups were compared by the paired $t$ test or repeatedmeasures analysis of variance with post hoc comparison using the Dunnett test as appropriate.

\section{Results}

OPCAB could be successfully performed in all patients without conversion to on-pump CABG or any newly developed segmental wall motion abnormalities after grafting and postoperative electrocardiographic changes indicative of myocardial infarction. None of the patients required inotropic support during the perioperative period. Also, during the stay in the ICU postoperatively, none of the patients had any neurologic, hepatic, or renal complications. Patients' characteristics and operative data were similar between the groups (Tables 1 and 2).

Dynamic and static pulmonary compliances were significantly decreased compared with baseline values in both groups after sternum closure without any intergroup differences (Table 3). After sternum closure, $\mathrm{PaO}_{2}$ was significantly decreased only in the control group compared with baseline value $(P<.0001)$ and was significantly higher in the mannitol group $(P=.0001$ for $\mathrm{T} 2$ and $<.0001$ for
TABLE 2. Operative data

\begin{tabular}{lcc}
\hline & $\begin{array}{c}\text { Control group } \\
(\mathbf{n}=\mathbf{2 5})\end{array}$ & $\begin{array}{c}\text { Mannitol group } \\
(\mathbf{n}=\mathbf{2 5})\end{array}$ \\
\hline Operation time (min) & $370 \pm 56$ & $371 \pm 66$ \\
No. of grafts per patient & $3.2 \pm 0.9$ & $3.5 \pm 0.8$ \\
Total anastomosis time (min) & $52 \pm 19$ & $53 \pm 18$ \\
LAD anastomosis (n) & 25 & 25 \\
$\quad$ Intracoronary shunt (n) & 25 & 25 \\
Anastomosis time (min) & $16 \pm 6$ & $17 \pm 6$ \\
LCx anastomosis (n) & 24 & 21 \\
Intracoronary shunt (n) & 17 & 14 \\
Anastomosis time (min) & $17 \pm 5$ & $15 \pm 4$ \\
RCA anastomosis (n) & 20 & 18 \\
Intracoronary shunt $(\mathrm{n})$ & 14 & 11 \\
Anastomosis time $(\mathrm{min})$ & $16 \pm 8$ & $15 \pm 5$ \\
Amount of infused NE ( $\mu \mathrm{g})$ & $292 \pm 270$ & $286 \pm 272$ \\
\hline
\end{tabular}

Data are expressed as mean \pm SD or number of patients, and all $P$ values were not significant. $L A D$, Left anterior descending coronary artery; $L C x_{i}$ left circumflex coronary artery; $R C A$, right coronary artery; $N E_{\text {, }}$ norepinephrine.

T2-T1, Table $3 *)$. Time to extubation was significantly faster in the mannitol group $(P=.002$, Table 3$)$. The length of stay in the ICU was also significantly shorter in the mannitol group $(P<.0001)$. Postoperative CK-MB level was significantly increased in both groups compared with the preoperative level and was lower in the mannitol group without statistical significance $(P=.058$ for T2 and .062 for T2-T1, Table 3). Number of patients with CK-MB elevations greater than 3 times the upper limit of normal was significantly greater in the control group $(P=.022$, Table 3$)$. Urine output during the operation was significantly greater in the mannitol group $(P<.0001)$; however, total amount of infused fluids and net fluid balance were all similar between the groups (Table 4). Serum $\mathrm{Na}^{+}$level showed no significant changes between the groups throughout the study period (Table 4).

Hemodynamic variables were comparable between the groups except the central venous pressure, mean pulmonary arterial pressure, and PCWP, which were significantly lower in the mannitol group during left circumflex coronary artery grafting (Table 5). In contrast to the control group, mean pulmonary arterial pressure and PCWP of the mannitol group did not significantly increase during left circumflex grafting compared with baseline values (Table 5).

\section{Discussion}

Infusion of mannitol before grafting during multivessel OPCAB yielded beneficial effects with regard to preservation of $\mathrm{PaO}_{2}$ during the intraoperative period, faster time to extubation, and shorter length of stay in the ICU without

*TO, 1 day before surgery; $T 1,15$ minutes after induction of anesthesia; T2, 15 minutes after sternum closure; $T 24,24$ hours after surgery. 
TABLE 3. Pulmonary variables and CK-MB level

\begin{tabular}{|c|c|c|c|}
\hline & Time & Control group $(n=25)$ & Mannitol group $(n=25)$ \\
\hline \multirow[t]{3}{*}{ Dynamic lung compliance $\left(\mathrm{mL} / \mathrm{cm} \mathrm{H}_{2} \mathrm{O}\right)$} & $\mathrm{T} 1$ & $38 \pm 7$ & $38 \pm 8$ \\
\hline & $\mathrm{T} 2$ & $33 \pm 8^{*}$ & $34 \pm 7^{*}$ \\
\hline & $\mathrm{T} 2-\mathrm{T} 1$ & $-4.2 \pm 5.6$ & $-4.3 \pm 6.7$ \\
\hline \multirow[t]{3}{*}{ Static lung compliance $\left(\mathrm{mL} / \mathrm{cm} \mathrm{H}_{2} \mathrm{O}\right)$} & $\mathrm{T} 1$ & $53 \pm 14$ & $52 \pm 11$ \\
\hline & $\mathrm{T} 2$ & $49 \pm 13^{*}$ & $46 \pm 10^{*}$ \\
\hline & $\mathrm{T} 2-\mathrm{T} 1$ & $-6.0 \pm 10.8$ & $-5.3 \pm 8.3$ \\
\hline \multirow[t]{3}{*}{$\mathrm{PaO}_{2}\left(\mathrm{~mm} \mathrm{Hg}, \mathrm{FlO}_{2}\right.$ of 0.6$)$} & $\mathrm{T} 1$ & $233 \pm 50$ & $218 \pm 41$ \\
\hline & $\mathrm{T} 2$ & $169 \pm 57^{*}$ & $221 \pm 39 \dagger$ \\
\hline & $\mathrm{T} 2-\mathrm{T} 1$ & $-63 \pm 59$ & $4 \pm 48 \dagger$ \\
\hline Time to extubation (min) & & $703 \pm 294$ & $483 \pm 125 \dagger$ \\
\hline Length of stay in the ICU (d) & & $2.6 \pm 0.7$ & $1.6 \pm 0.5 \dagger$ \\
\hline \multirow[t]{3}{*}{ CK-MB (ng/mL) } & T0 & $2.2 \pm 0.9$ & $2.2 \pm 0.8$ \\
\hline & T24 & $11.7 \pm 11.5^{*}$ & $7.0 \pm 2.9^{*}$ \\
\hline & T24-T0 & $9.7 \pm 11.9$ & $4.9 \pm 2.9$ \\
\hline CK-MB elevation $>3 \times$ the upper limit of normal $(n)$ & & $6 \dagger$ & 0 \\
\hline
\end{tabular}

Data are expressed as number of patients or mean \pm SD. $T 1,15$ minutes after induction of anesthesia; $T 2,15$ minutes after sternum closure; $T 0,1$ day before surgery; $T 24,24$ hours after surgery; $\mathrm{FIO}_{2}$, inspired oxygen fraction; $I C U$, intensive care unit; $C K-M B$, creatine kinase MB. $* P<.05$ compared with values at $\mathrm{T} 1$ or $\mathrm{T} 0$ in each group; $\uparrow P<.05$ between the groups.

affecting total amount of infused fluids, net fluid balance, serum $\mathrm{Na}^{+}$concentration, and hemodynamics. In addition, a significantly greater number of patients had CK-MB elevations more than 3 times the upper limit of normal in the control group, and, although without statistical significance, there was a trend toward less postoperative CK-MB release in patients treated with mannitol.

TABLE 4. Fluid balance and serum sodium level

\begin{tabular}{lcc}
\hline & $\begin{array}{c}\text { Control group } \\
(\mathbf{n}=\mathbf{2 5})\end{array}$ & $\begin{array}{c}\text { Mannitol group } \\
(\mathbf{n}=\mathbf{2 5})\end{array}$ \\
\hline $\begin{array}{l}\text { Intraoperative } \\
\text { Input (mL) } \\
\text { Crystalloid }\end{array}$ & $2483 \pm 879$ & $2742 \pm 867$ \\
$\quad$ Colloid & $1039 \pm 313$ & $1110 \pm 305$ \\
pRBCs (u/n) & $14 / 8$ & $11 / 6$ \\
Urine output $(\mathrm{mL})$ & $727 \pm 314$ & $1202 \pm 521^{*}$ \\
Net balance $(\mathrm{mL})$ & $2795 \pm 900$ & $2698 \pm 1077$ \\
Postoperative $12 \mathrm{~h}$ & & \\
Input (mL) & & \\
$\quad$ Crystalloid & $2407 \pm 816$ & $2339 \pm 576$ \\
pRBCs (u/n) & $1 / 1$ & $0 / 0$ \\
Urine output $(\mathrm{mL})$ & $1267 \pm 544$ & $983 \pm 428$ \\
CT drainage $(\mathrm{mL})$ & $296 \pm 127$ & $406 \pm 249$ \\
Net balance $(\mathrm{mL})$ & $450 \pm 700$ & $761 \pm 241$ \\
Serum sodium $(\mathrm{mEq} / \mathrm{L})$ & & $142 \pm 2$ \\
T1 & $141 \pm 2$ & $141 \pm 2$ \\
T2 & $141 \pm 3$ &
\end{tabular}

Data are expressed as mean $\pm S D$ or number of units/number of patients (u/n). pRBCs, Packed red blood cells; CT, chest tube; $T 1,15$ minutes after induction of anesthesia; T2, 15 minutes after sternum closure; $* P<.05$ between the groups.
Despite avoiding $\mathrm{CPB}, \mathrm{OPCAB}$ is associated with a decrease in $\mathrm{PaO}_{2}$ and pulmonary function similar to onpump CABG with no difference in time to extubation. ${ }^{7,8}$ Also, interruption of coronary blood flow for bloodless anastomoses during multivessel OPCAB may impose cumulative ischemia-reperfusion myocardial injury. ${ }^{9,10}$ Therefore, strategies for minimizing pulmonary impairment and myocardial injury should be considered.

Mannitol is an osmotic diuretic with free radical scavenging properties widely used in the field of cardiac surgery, administered in doses ranging from 0.25 to $1.5 \mathrm{~g} / \mathrm{kg}$. It can be administered in the pump prime and cardioplegic solution with beneficial effects on the kidneys, lungs, brain, and heart. ${ }^{13,20}$ It has been shown to decrease lung water content and maintain pulmonary function after CPB by its osmotic diuretic action and to limit ischemia-induced thromboxane synthesis. ${ }^{14,15}$ In addition, mannitol is associated with transient increase in coronary blood flow and cardiac output and reduction in the extent of myocardial damage through its hydroxyl radical scavenging properties. ${ }^{16-18,21,22}$ Mannitol also decreases the blood viscosity and may enhance microcirculation. $^{23}$ Therefore, we have hypothesized that mannitol may exert favorable effects with regard to preserving oxygenation and decreasing cumulative ischemia-reperfusion myocardial injury in patients undergoing multivessel OPCAB. However, experience using mannitol during $\mathrm{OPCAB}$ is limited and mannitol is not free of side effects. During mannitol-induced osmotic diuresis, usually more water than $\mathrm{Na}^{+}$is lost and may lead to hypovolemia and hypernatremia. ${ }^{11}$ Also, owing to its acute plasma volume expansion effect, rapid infusion of mannitol may precipitate congestive heart failure. ${ }^{12}$ 
TABLE 5. Hemodynamic data

\begin{tabular}{|c|c|c|c|c|c|}
\hline & Group (n $=25$, each) & TO & T1 & T2 & T3 \\
\hline \multirow[t]{2}{*}{ HR (beats/min) } & Control & $59 \pm 7$ & $61 \pm 9$ & $67 \pm 12^{*}$ & $68 \pm 12^{*}$ \\
\hline & Mannitol & $62 \pm 7$ & $64 \pm 8$ & $70 \pm 13^{*}$ & $74 \pm 12^{*}$ \\
\hline \multirow[t]{2}{*}{$\mathrm{MAP}(\mathrm{mm} \mathrm{Hg})$} & Control & $73 \pm 9$ & $74 \pm 11$ & $78 \pm 10$ & $77 \pm 10$ \\
\hline & Mannitol & $77 \pm 11$ & $76 \pm 13$ & $76 \pm 8$ & $81 \pm 11$ \\
\hline \multirow[t]{2}{*}{ MPAP (mm Hg) } & Control & $17 \pm 4$ & $18 \pm 4$ & $21 \pm 5^{*}$ & $17 \pm 3$ \\
\hline & Mannitol & $16 \pm 3$ & $18 \pm 4$ & $18 \pm 5 \dagger$ & $16 \pm 3$ \\
\hline \multirow[t]{2}{*}{ CVP (mm Hg) } & Control & $9 \pm 3$ & $8 \pm 2$ & $12 \pm 3^{*}$ & $9 \pm 3$ \\
\hline & Mannitol & $8 \pm 2$ & $8 \pm 2$ & $10 \pm 3^{*} \dagger$ & $8 \pm 2$ \\
\hline \multirow[t]{2}{*}{ PCWP (mm Hg) } & Control & $12 \pm 4$ & $12 \pm 3$ & $15 \pm 5^{*}$ & $13 \pm 3$ \\
\hline & Mannitol & $12 \pm 3$ & $12 \pm 3$ & $13 \pm 3 \dagger$ & $11 \pm 3$ \\
\hline \multirow[t]{2}{*}{$\mathrm{SvO}_{2}(\%)$} & Control & $80 \pm 4$ & $82 \pm 6$ & $67 \pm 9^{*}$ & $74 \pm 7^{*}$ \\
\hline & Mannitol & $81 \pm 3$ & $82 \pm 6$ & $65 \pm 11^{*}$ & $73 \pm 7^{*}$ \\
\hline \multirow[t]{2}{*}{$\mathrm{Cl}\left(\mathrm{L} \cdot \min ^{-1} \cdot \mathrm{m}^{-2}\right)$} & Control & $2.9 \pm 0.5$ & $2.6 \pm 0.4$ & $2.0 \pm 0.3^{*}$ & $2.6 \pm 0.4^{*}$ \\
\hline & Mannitol & $3.0 \pm 0.6$ & $2.8 \pm 0.5$ & $2.1 \pm 0.4^{*}$ & $2.6 \pm 0.4^{*}$ \\
\hline
\end{tabular}

Data are expressed as mean \pm SD. T0, 15 minutes after induction of anesthesia; $T 1,10$ minutes after infusion of either mannitol or normal saline; $T 2,10$ minutes after stabilizer application for circumflex grafting; $T 3,15$ minutes after sternum closure; $H R$, heart rate; MAP, mean arterial pressure; MPAP, mean pulmonary arterial pressure; $C V P$, central venous pressure; $P C W P$, pulmonary capillary wedge pressure; $S_{V 0}{ }_{2}$, mixed venous oxygen saturation; $\mathrm{Cl}$, cardiac index. $* P<.05$ compared with values at T0 in each group; $\dagger P<.05$ between group comparisons at each time point of measurement.

In this study, even though intraoperative urine output was significantly increased in the mannitol group, total fluid and net fluid balance in the intraoperative as well as in the postoperative period were similar between the groups. Amount of infused norepinephrine during the operation and $\mathrm{Na}^{+}$level before and after mannitol or normal saline infusion were also similar between the groups. In addition, central venous pressure, PCWP, and other hemodynamic variables showed no clinically significant differences between the groups. Regarding these results, preserved oxygenation in the mannitol group may be attributable to osmotic diuresis and subsequent reduction of increased interstitial water content of the lung without eliciting hypovolemia or adverse hemodynamic effects. Even though we could not observe any significant differences in pulmonary compliances at the end of the operation between the groups, the finding that time to extubation was significantly faster in the mannitol group can be regarded as an important clinical benefit of mannitol infusion. However, the results of this study should not be extended to patients with compromised renal clearance. The theoretical volume of distribution of mannitol is the entire extracellular space and is rapidly eliminated almost exclusively by renal clearance. ${ }^{11,12}$ Therefore, it may be sequestered in the interstitial space and may cause an increase in extravascular water content in case of impaired renal clearance.

Elevation in CK-MB level greater than 3 times the upper limit of normal after on-pump CABG or percutaneous coronary intervention has been shown to be associated with increased mortality. ${ }^{24-26}$ The fact that none of the patients in the mannitol group and a significantly greater number of patients in the control group had a CK-MB level more than
3 times the upper limit of normal despite similar preoperative and intraoperative characteristics between the groups can also be considered as a beneficial effect of mannitol. Although there was a trend toward less CK-MB release in the mannitol group, the finding that there was no statistically significant difference in CK-MB levels between the groups may be attributable to multiple factors. In our study, intracoronary shunt has been used during left anterior descending coronary artery grafting in all patients and also in some patients during left circumflex and right coronary artery grafting. Even though the numbers were similar between the groups, since intracoronary shunt provides some distal flow during grafting procedure, this might have affected our result. ${ }^{27}$ The concentration and timing of mannitol infusion might have affected the result as well. Free radical generation is greatest during early postischemic reperfusion; therefore, infusion at the start of reperfusion should yield the greatest effect in terms of myocardial preservation. ${ }^{17,18}$ In contrast to on-pump CABG, where the application and release of aortic crossclamping is most responsible for myocardial ischemia-reperfusion injury, various degrees of ischemia-reperfusion injury may result at each grafting during OPCAB. ${ }^{9,10}$ Considering immediate onset and an elimination half-life of 2 to 4 hours, we thought it would be most appropriate to infuse mannitol just before the first grafting procedure. However, the optimal concentration and timing of mannitol infusion with regard to myocardial protection can be a limitation of this study. In addition, considering the difference in SD of the postoperative CK-MB values between the groups, a larger sample size may be required to be well powered. 
Another limitation of this study is that we have excluded patients with pre-existing lung parenchymal disease, unstable angina, and decreased left ventricular ejection fraction who might be more susceptible to significant postoperative impairment of oxygenation and increase in cardiac enzyme release. Whether the same efficacy and safety can be observed in these patients needs to be validated through further studies.

In conclusion, mannitol could be safely used without adverse side effects in patients undergoing multivessel OPCAB with favorable effects on oxygenation, time to extubation, length of stay in the ICU, and CK-MB release. Therefore, infusion of mannitol may be considered as a potential therapeutic modality for preserving oxygenation with myocardial protective effect in patients without impaired renal clearance undergoing multivessel OPCAB.

\section{References}

1. Puskas JD, Wright CE, Ronson RS, Brown WM, Gott JP, Guyton RA. Off pump multivessel coronary bypass via sternotomy is safe and effective. Ann Thorac Surg. 1998;66:1068-72.

2. Kobayashi J, Tashiro T, Ochi M, Yaku H, Watanabe G, Satoh T, et al. Early outcome of a randomized comparison of off-pump and on-pump multiple arterial coronary revascularization. Circulation. 2005;112: 338-43.

3. Kuduvalli M, Newall N, Stott A, Grayson AD, Fabri BM. Impact of avoiding cardiopulmonary bypass for coronary surgery on perioperative cardiac enzyme release and survival. Eur J Cardiothorac Surg. 2006;29:729-35.

4. Cartier R, Brann S, Dagenais F, Martineau R, Couturier A. Systematic off-pump coronary artery revascularization in multivessel disease: experience of three hundred cases. J Thorac Cardiovasc Surg. 2000; 119:221-9.

5. Van Oeveren W. Leukocyte and platelet activation during extracorporeal circulation. Cells Mater. 1994;4:187-95.

6. Wan S, LeClerc JL, Vincent JL. Inflammatory response to cardiopulmonary bypass: mechanisms involved and possible therapeutic strategies. Chest. 1997;112:676-92.

7. Montes FR, Maldonado JD, Paez S, Ariza F. Off-pump versus onpump coronary artery bypass surgery and postoperative pulmonary dysfunction. J Thorac Cardiovasc Surg. 2004;18:698-703.

8. Kochamba GS, Yun KL, Pfeffer TA, Sintek CF, Khonsari S. Pulmonary abnormalities after coronary arterial bypass grafting operation: cardiopulmonary bypass versus mechanical stabilization. Ann Thorac Surg. 2000;69:1466-70.

9. Kwak YL. Reduction of ischemia during off-pump coronary artery bypass graft surgery. J Cardiothorac Vasc Anesth. 2005;19:667-77.
10. Puskas JD, Vinten-Johansen J, Murakai S, Guyton R. Myocardial protection for off-pump coronary artery bypass surgery. Semin Thorac Cardiovasc Surg. 2001;13:82-8.

11. Paczynski RP. Osmotherapy. Basic concepts and controversies. Crit Care Clin. 1997;13:105-29.

12. Nau R. Osmotherapy for elevated intracranial pressure: a critical reappraisal. Clin Pharmacokinet. 2000;38:23-40.

13. Poullis M. Mannitol and cardiac surgery. Thorac Cardiovasc Surg. 1999;47:58-62.

14. Paterson IS, Klausner JM, Goldman G, Pugatch R, Feingold H, Allen $\mathrm{P}$, et al. Pulmonary edema after aneurysm surgery is modified by mannitol. Ann Surg. 1989;210:796-801.

15. Toung TJK, Chang Y, Lin J, Bhardwaj A. Increase in lung and brain water following experimental stroke: effect of mannitol and hypertonic saline. Crit Care Med. 2005;33:203-8.

16. Ouriel K, Ginsburg ME, Patti CS, Pearce FJ, Hicks GL. Preservation of myocardial function with mannitol reperfusate. Circulation. 1985; 72:254-8.

17. Casale AS, Bulkley GB, Bulkley BH, Flaherty JY, Gott VL, Gardner TJ. Oxygen free-radical scavengers protect the arrested globally ischemic heart upon reperfusion. Surg Forum. 1983;34:313-6.

18. Shlafer M, Kane PF, Kirsh MM. Superoxide dismutase plus catalase enhances the efficacy of hypothermic cardioplegia to protect globally ischemic, reperfused heart. J Thorac Cardiovasc Surg. 1982;83:830-9.

19. French JK, White HD. Clinical implications of the new definition of myocardial infarction. Heart. 2004;90:99-106.

20. Fisher AR, Jones P, Barlow P, Kennington S, Saville S, Farrimond J, et al. The influence of mannitol on renal function during and after open-heart surgery. Perfusion. 1998;13:181-6.

21. Hutton I, Curry GC, Templeton GH, Willerson JT. Influence of hypertonic mannitol on regional myocardial blood flow and ventricular performance in awake, intact dogs with prolonged coronary artery occlusion. Cardiovasc Res. 1975;9:409-19.

22. Willerson JT, Curry GC, Atkins JM, Parkey R, Horowitz LD. Influence of hypertonic mannitol on ventricular performance and coronary blood flow in patients. Circulation. 1975;51:1095-100.

23. Burke AM, Quest DQ, Chien S, Cerri C. The effects of mannitol on blood viscosity. J Neurosurg. 1981;55:550-3.

24. Costa MA, Carere RG, Lichtenstein SV, Foley DP, de Valk V, Lindenboom $\mathrm{W}$, et al. Incidence, predictors, and significance of abnormal cardiac enzyme rise in patients treated with bypass surgery in the Arterial Revascularization Therapies Study (ARTS). Circulation. 2001;104:2689-93.

25. Ghazzal Z, Ashfaq S, Morris DC, Douglas JS, Marshall JJ, King SB, et al. Prognostic implication of creatine kinase release after elective percutaneous coronary intervention in the pre-IIb/IIIa antagonist era. Am Heart J. 2003;145:1006-12.

26. Bhatt DL, Topol EJ. Does creatinine kinase-MB elevation after percutaneous coronary intervention predict outcomes in 2005? Periprocedural cardiac enzyme elevation predicts adverse outcomes. Circulation. 2005;112:906-15.

27. Gurbuz A, Emrecan B, Yilik L, Ozsoyler I, Kestelli M, Ozbek C, et al. Intracoronary shunt reduces postoperative troponin leaks: a prospective randomized study. Eur J Cardiothorac Surg. 2006;29:186-9. 